\title{
Reforzando Su Techo ${ }^{1}$ \\ 1
}

Hal S. Knowles, III, Kathleen C. Ruppert, Karla A. Lenfesty y Barbara Haldeman²

El techo ayuda a mantener su hogar confortable y seco. Pero durante los fuertes vientos de un huracán, un techo mal diseñado ó mal mantenido puede fracasar. Aquí hay algunos consejos para reforzar su techo.

\section{¿Por Qué El Diseño de Un Techo Es Importante?}

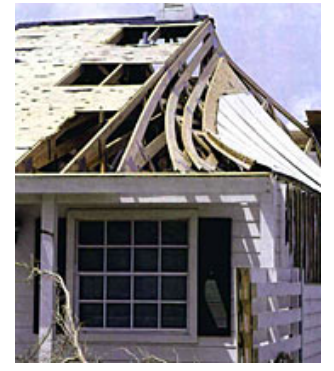

Fuente de información: Institute for Business \& Home
Los techos con un ángulo muy inclinado proporcionan un mal funcionamiento contra vientos horizontales. Techos con un ángulo muy bajo aumentan la elevación vertical provocada por los vientos. Ángulos entre 3:12 y 6:12 (dirección horizontal:elevación vertical) son considerados los mas rápidos.

Ambos techos con caídas y techos con diseño de pared al final (gable) son comunes en la Florida. Por su diseño, techos con caídas son más resistentes a fuertes vientos.

Techos gable pueden ser construidos más seguros con algunas mínimas mejoras.

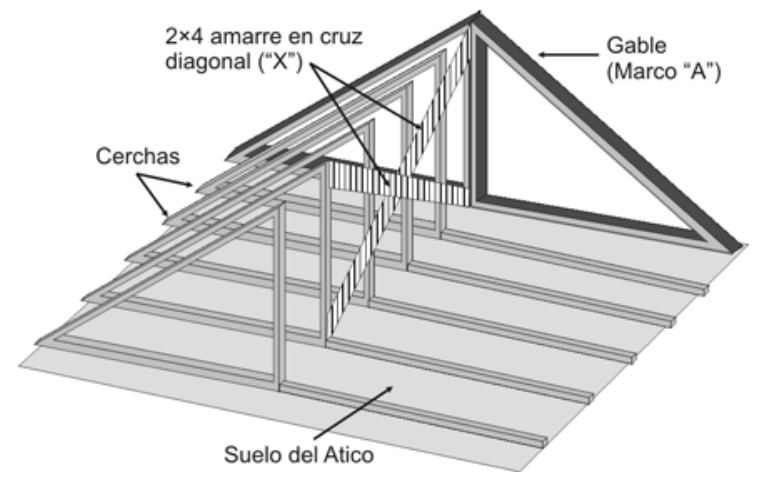

\section{Amarre en Cruz ("X") de Techos Gable (Marco "A" ó "A" Frame)}

Primero, instale el amarre en cruz diagonal entre las cerchas del techo gable y la cuarta cercha de atrás. Asegúrese, amarre en cruz "X” el marco "A"

\section{Amarre Para Evitar El Efecto Domino}

Segundo, instalar los amarres de cerchas horizontales para prevenir que las cerchas sean empujadas juntas por fuertes vientos. Esto es mostrado en la foto de la izquierda. Recuerde evitar el "efecto domino".

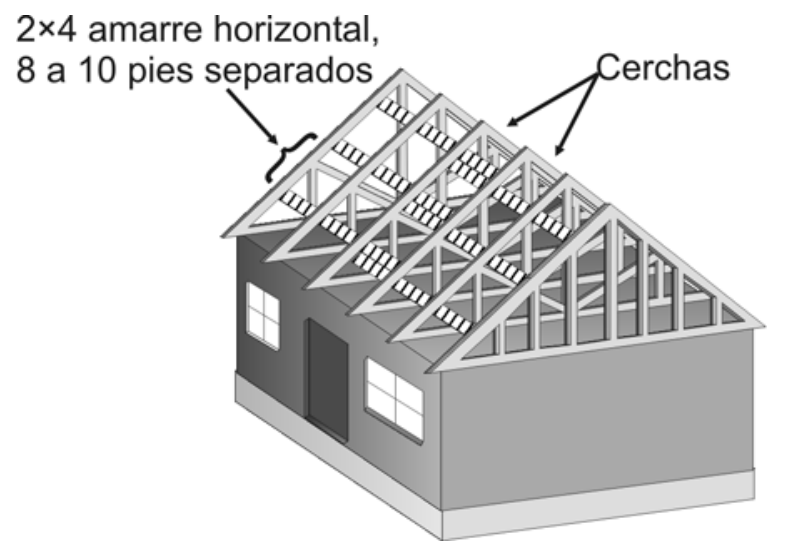

Tercero, instale obturadores en los ventiladores en la pared final del techo gable. Si usted esta construyendo una casa nueva con techo gable, considere usar pared de construcción continua. Esto crea una unidad sólida en el marco de la pared, desde el suelo hacia el techo donde el gable termina en la casa.

1. Este documento es Parte 4 de 5 en Educación + Acción = Series de Mitigación en Daños de Vientos. Día de publicación: Noviembre 2005.

2. Hal S. Knowles, III, Coordinador, Program for Resource Efficient Communities; Kathleen C. Ruppert, Científico de Extensión Asociado, Florida Energy Extension Service; Karla A. Lenfesty, Especialista del Programa de Mitigación en Daños de Tormentas de Vientos, St. Lucie County Cooperative Extension, Institute of Food and Agricultural Sciences, University of Florida; Barbara Haldeman, Asistente Editorial, Florida Energy Extension Service.

The Institute of Food and Agricultural Sciences (IFAS) es un Empleador de igualdad de oportunidad autorizado para proveer investigación, información educacional y otros servicios a individuos e instituciones que funcionen sin discriminación de raza, credo, color, religión, edad, inhabilidad, sexo, orientación sexual, estado civil, origen de nacionalidad, opinión ó afiliación política. Para información de cómo obtener otras publicaciones de extensión, contacte la oficina de Cooperative Exntension Service de su Condado. Florida Cooperative Extension Service / Institute of Food and Agricultural Sciences / University of Florida / Larry R. Arrington, Decano 


\section{Crear Una Vía De Carga Continua}

Una casa es un sistema de partes conectadas. Si hay alguna conección débil en el sistema, toda la casa podría dañarse. Por eso es importante crear vías de carga continua entre el suelo y la parte alta de su casa. Esto unifica la estructura vertical de su casa y disminuye la elevación vertical de la fuerza de los vientos de huracán.

Una vía de carga continua requiere que el techo de su casa sea anclado a las paredes de la casa, del segundo piso al primer piso y las paredes a la base de la estructura. Esto se puede hacer utilizando correas de huracán para las conecciones del techo a la pared y de piso a piso y anclar tornillos para la conección de pared a la base de la estructura.

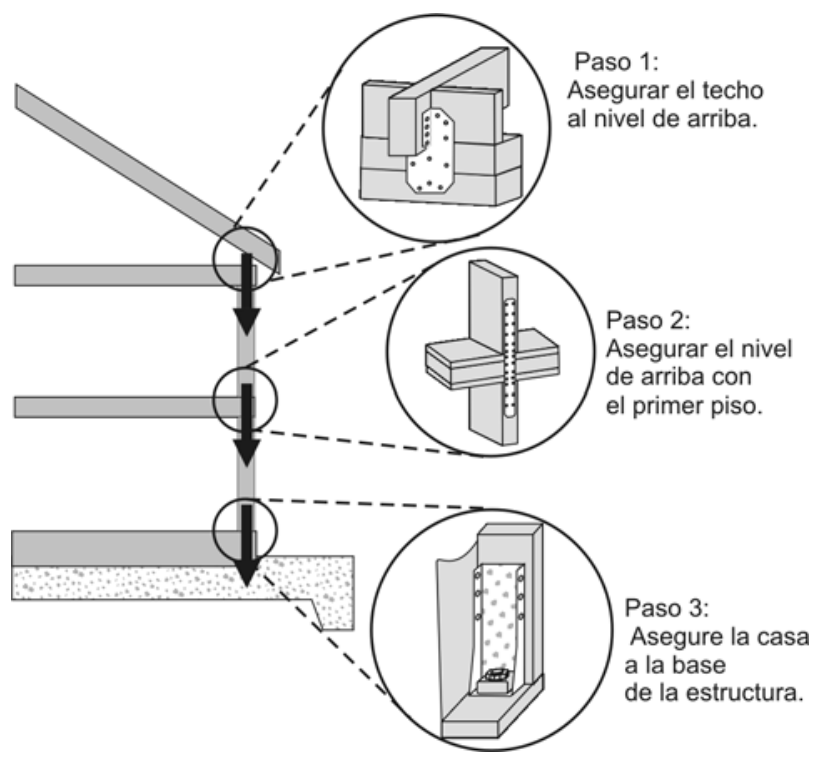

Hay muchas clases de correas de huracán y otros tipos de materiales para anclar disponibles. Asegúrese de escoger productos aprobados por el Miami-Dade County Building Code. Siempre use las especificaciones de instalación del fabricante.

\section{Instalación Apropiada De Hojas De Plywood y Tejas}

Cuando las tejas de los techos, hojas de plywood u otros materiales de techo son instalados inapropiadamente ó con materiales por debajo del estándar, estos pueden ser arrancados del techo de su casa. Esto permite que los vientos y el agua penetren, dañando su casa. También, estos materiales pueden convertirse en escombros peligrosos en el aire ó llevados por el viento durante una tormenta. Técnicas apropiadas para atar pueden prevenir que los materiales sean arrancados de una casa durante una tormenta severa.
Conectar las hojas de plywood al marco del techo con clavos de diez centavos de peso ó clavos de ocho centavos de peso con anillos. A lo largo del borde, coloque los clavos a cuatro pulgadas de distancia de cada clavo y hacia el medio de la hoja de plywood, coloque los clavos a seis pulgadas de distancia de cada clavo.

Los clavos con anillos proveen mayor capacidad de sostenimiento por el refuerzo de los anillos. Estos anillos sujetan las hojas de plywood al marco y proveen mayor resistencia a fuertes elevaciones verticales.

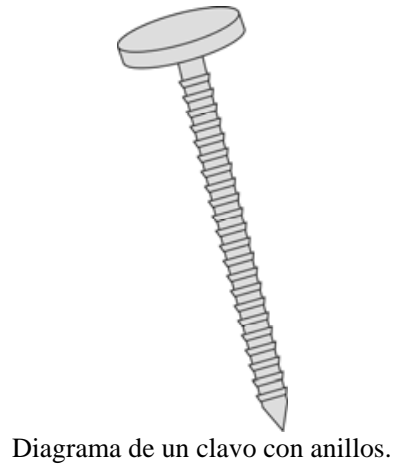

\section{Otros recursos}

Federal Alliance for Safe Homes www.flash.org

Federal Emergency Management Agency | Disaster Prevention \& Preparation Library www.fema.gov/library/prepandprev.shtm

Florida Division of Emergency Management | Information Page www.floridadisaster.org/DEMinformation.htm

Institute for Business and Home Safety www.ibhs.org

University of Florida | Disaster Handbook http://disaster.ifas.ufl.edu/ 